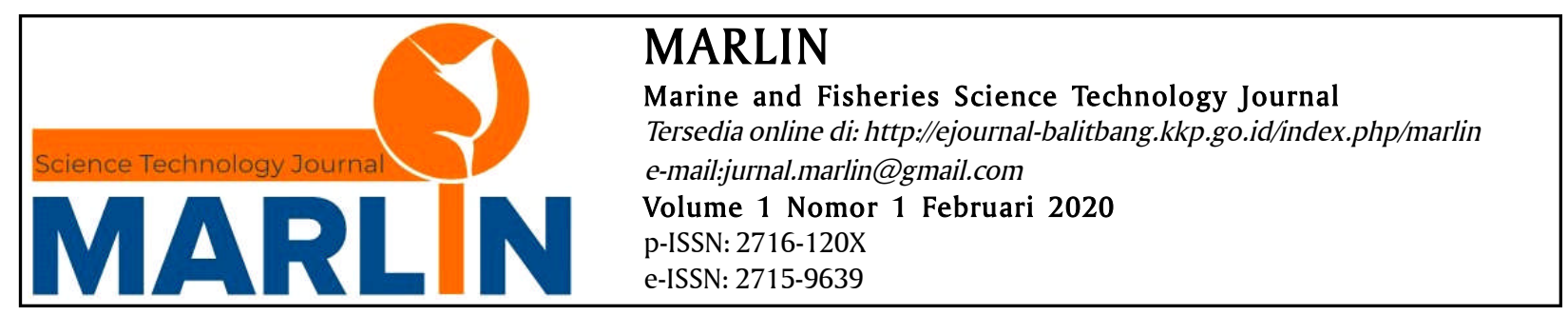

\title{
ANALISA NUMERIK TSUNAMI PANGANDARAN DAN IMPLIKASINYA TERHADAP MITIGASI BENCANA
}

\section{NUMERICAL ANALYSIS OF PANGANDARAN TSUNAMI AND ITS IMPLICATIONS ON DISASTER MITIGATION}

\author{
Lulut Alfaris*1, Arif Baswantara ${ }^{1}$ dan Suhernalis ${ }^{1}$ \\ ${ }^{1}$ Program Studi Teknologi Kelautan, Politeknik Kelautan dan Perikanan Pangandaran, Jl. Raya Babakan KM. 02 Pangandaran, 46396- \\ Jawa Barat, Indonesia \\ Teregistrasi I tanggal: 30 Januari 2020; Diterima setelah perbaikan tanggal: 06 Februari 2020; \\ Disetujui terbit tanggal: 14 Februari 2020
}

\begin{abstract}
ABSTRAK
Lempeng Eurasia adalah lempeng tektonik terbesar ketiga yang berada di daerah Eurasia, daratan yang terdiri dari benua Eropa dan Asia. Lempeng Sunda merupakan bagian dari Lempeng Eurasia yang rumit secara tektonik dan aktif secara seismik.Adapun tujuan penelitian ini adalah untuk menentukan karakterisik pola patahan akibat gempabumi tanggal 17 Juli 2006 di Laut Selatan Jawa dengan sumber data dari katalog gempa bumi USGS. Analisis bola fokus bahwa gempa tanggal $17 \mathrm{Juli} 2006$ dengan koordinat $9.3^{\circ} \mathrm{S}$ dan $107.4^{\circ} \mathrm{E}$ adalah kombinasi sesar mendatar dan sesar naik atau jenis sesar ini disebut juga oblique. Hasil analisis 3D Focal Mechanism dan perhitungan rumus empiris menunjukkan bahwa terjadinya penjalaran gelombang tsunami (Tsunami Travel Time) kedaerah pantai dipesisir Jawa selatan mempunyai waktu sekitar 30 menit, sehingga diperlukan kesiapsiagaan dalam menghadapi bencana.
\end{abstract}

Kata Kunci: Lempeng tektonik; tsunami travel time; gempa bumi

\section{ABSTRACT}

The Eurasian Plate is the third largest tectonic plate in the Eurasia region, a land consisting of Europe and Asia. The Sunda Plate is part of the Eurasian Plate which is complicated by tectonics and seismically active. The purpose of this study is to determine the characteristics of the fault patterns due to the earthquake on 17 July 2006 in the South Sea of Java with data sources from the USGS earthquake catalog. Focus ball analysis that the earthquake on July 17, 2006 with coordinates $9.3^{\circ} \mathrm{S}$ and $107.4^{\circ} \mathrm{E}$ is a combination of horizontal faults and rising faults or this type of fault is also called oblique. The results of the 3D Focal Me chanism analysis and the calculation of empirical formulas indicate that the occurrence of tsunami wave propagation in the coastal areas of South Java approximately 30 minutes, so that preparedness is needed in the face of disasters.

Keywords: Tectonic plate; tsunami travel time; earthquake 


\section{PENDAHULUAN}

Indonesia terletak pada batas pertemuan tiga lempeng besar dunia yang sangat aktif yaitu lempeng Eurasia, lempeng Pasifik, dan lempeng Indo-Australia serta satu lempeng mikro yaitu lempeng mikro Filipina, karena itu maka wilayah Indonesia sangat rawan terhadap bencana gempa tektonik. Indonesia sebagai negara yang terletak di kawasan Zona Seismik Asia Tenggara, merupakan salah satu negara dengan aktifitas seismik paling aktif bahkan teraktif di dunia (Aydan, 2008).

Lempeng laut Sunda merupakan lempeng bagian dari Lempeng Euraisa, yang merupakan lempeng diantara Eurasia dan Australia, kondisi ini mengakibatkan kegempaan daerah Jawa dan sekitarnya terkonsentrasi di sebagian besar wilayah selatan dari Pulau Jawa dimana aktivitas kegempaan sering terjadi.

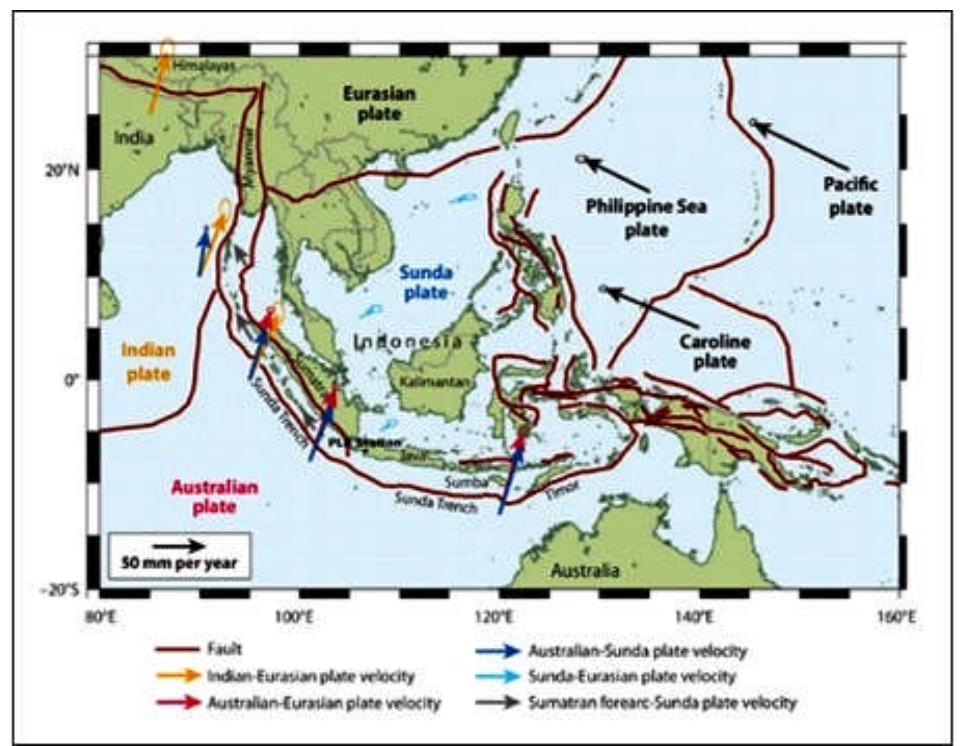

Gambar 1. Zona Lempeng Indonesia.

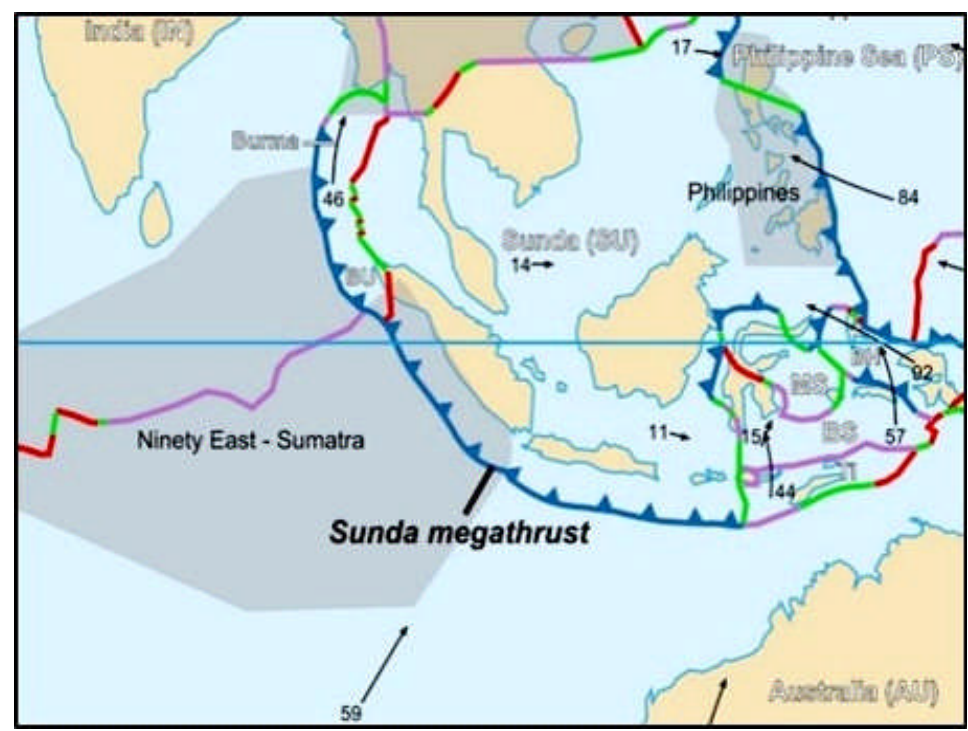

Gambar 2. Subduksi Selat Sunda.

Gempabumi dengan magnitude 7.2 SR tanggal 17 Juli 2006 merupakan salah satu contoh gempa berskala besar yang terjadi di Laut Selatan Jawa dengan koordinat $9.3^{\circ} \mathrm{S}$ dan $107.4^{\circ}$ E. Secara toritis, gempa yang terjadi sudah memenuhi kriteria gempa yang mengakibatkan tsunami. Dari kejadian tsunami ini telah menimbulkan banyak korban baik jiwa maupun materiil. Sehingga diperlukan untuk menganalisis gempa dan tsunami dalam konteks mitigasi bencana.

\section{Pemodelan Sumber Gempa}

Pemodelan sumber gempa bumi atau pembuatan model-model seismotektonik harus dilakukan dengan berdasarkan indikasi data geologi, geodesi, geofisika dan seismologi yang mengandung informasi struktur seismogenik menerus ataupun yang terpisah (discrete). Bertitik tolak dari data-data tersebut yang ada, Kertapati (2006) dan Irsyam et al. (2008) mengenali dan membedakan 
ada tiga lajur sumber gempa bumi di Wilayah Indonesia, yaitu:

a. Zona Penunjaman / Subduksi, yaitu jalur tempat terjadinya gempa bumi disekitar pertemuan antara dua lempeng dimana lempeng samudera menunjam ke dalam lempeng benua atau dua lempeng benua saling menumpu.

b. Zona patahan patahan kerak bumi dangkal "shallow crustal fault zone" tempat terjadinya gempa bumi di dalam kerak bumi dangkal.

c. Zona menyebar (diffuse) yaitu jalur sumber gempa yang diasumsikan sebagai daerah yang mempunyai potensi kegempaan yang sama.

\section{Pemodelan Tsunami}

Tsunami dapat dituliskan dalam bentuk model matematika. Model Matrix Tsunami ditulis dalam berbagai bentuk persamaan massa dan momentum

$$
\begin{gathered}
\frac{\partial n}{\partial t}+\frac{\partial u}{\partial x}+\frac{\partial v}{\partial y}+\frac{\partial w}{\partial z}=0 \\
\frac{\partial n}{\partial t}+u \frac{\partial u}{\partial x}+v \frac{\partial u}{\partial y}+w \frac{\partial u}{\partial z}+\frac{1 \partial p}{\rho \partial x}+\frac{1}{\rho}\left(\frac{\partial \tau x x}{\partial x}+\frac{\partial \tau x y}{\partial y}+\frac{\partial \tau x z}{\partial z}\right)=0 \\
\frac{\partial v}{\partial t}+u \frac{\partial v}{\partial x}+v \frac{\partial v}{\partial y}+w \frac{\partial v}{\partial z}+\frac{1 \partial p}{\rho \partial y}+\frac{1}{\rho}\left(\frac{\partial \tau x y}{\partial x}+\frac{\partial \tau y y}{\partial y}+\frac{\partial \tau y z}{\partial z}\right)=0 \\
g+\frac{1 \partial \rho}{\rho \partial z}=0
\end{gathered}
$$

Dimana :

$$
\begin{array}{ll}
x \text { dan } y & =\text { horizontal axis } \\
z & =\text { vertikal axis } \\
t & =\text { waktu } \\
h & =\text { aliran air } \\
n & =\text { tinggi gelombang diatas permukaan } \\
u, V \text { dan } W & =\text { kecepatan arah dari } \mathrm{x}, \mathrm{y} \text { dan } \mathrm{z} \\
g & =\text { kecepatan gravitasi }
\end{array}
$$

Berdasarkan catatan Latief et al. (2000), kejadian tsunami yang pernah terjadi di Indonesia sampai pada tahun 1999 sebanyak 105 kali kejadian tsunami, dimana $90 \%$ terjadi karena gempa tektonik, $9 \%$ oleh letusan gunung berapi, dan $1 \%$ karena tanah longsor. Menurut Kaharuddi et al. (2011) jenis gempabumi di dasar laut yang berpotensi menimbulkan tsunami memiliki sifat dan kondisi:

1. Kekuatan gempa diatas 6 SR.

2. Gempa bumi dangkal yaitu gempabumi di kedalaman lebih kecil dari $60 \mathrm{~km}$ dari permukaan laut.

3. Kedalaman air yang cukup ( $500-5000 \mathrm{~m})$. 4. Letak fokus gempa berada pada bagian luar tebing laut yang curam terhadap daratan (luar zona subduksi).

5. Terjadi pola pergerakan sesar secara vertikal.

Menurut Sutrisno (2007) episenter gempabumi adalah tempat asal mula terbentuknya tunami di laut. Kecepatan tsunami berbeda untuk setiap kedalaman laut yang berbeda, sehingga kecepatan tsunami yang menuju pantai berubah.

Non-linear Shallow Water Model (NSWM) umumnya dipakai oleh peneliti untuk simulasi run-up tsunami dan genangan tanah karena menawarkan kemampuan komputasi yang efisien dan kuat tanpa mengorbankan akurasi terlalu banyak dibandingkan dengan BTM. Olabarrieta et al. (2011) mengembangkan model CantabriaComcot-Tsunami-Claw (C3) dengan menyelesaikan bentuk konservatif dari persamaan Non-linier Shalllow Water Equations (NSWEs) untuk mensimulasikan perambatan tsunami dan run-up. Ha \& Cho (2015) mengusulkan model beda hingga dimodifikasi berdasarkan persamaan air dangkal dan menerapkannya untuk mensimulasikan propagasi tsunami di atas kawanan yang terendam.

Penentuan pola patahan gempa dalam penelitian ini menggunakan mekanisme bola focus. Dengan menentukan pola patahan, hasil yang diperoleh diharapkan berupa pola patahan yang dominan di daerah laut selatan Jawa. Penentuan pola patahan dominan Laut Selatan Jawa dikaitkan dengan gempa 7.7 SR tanggal 17 Juli 2006 untuk melihat proyeksi bola fokus yang didapat kemudian akan diketahui penyebab terjadinya tsunami pada gempa besar tersebut.

\section{METODE PENELITIAN}

Data kejadian gempa bumi dengan batas daerah penelitian yaitu $9.3^{\circ} \mathrm{S}$ dan $107.4^{\circ} \mathrm{E}$, kedalaman $12 \mathrm{Km}$ (gempa dangkal). Parameter gempa bumi yang digunakan dalam penelitian ini berupa lokasi episenter (sumber gempa bumi), serta parameter bola focus berupa data polarisasi awal gelombang gempa. Metode penelitian yang digunakan adalah metode analisis deskriptif.

Penelitian tentang analisis tingkat seismisitas dan periode ulang gempa bumi dengan metode kuadrat terkecil. Data yang digunakan dalam penelitian ini merupakan data sekunder, yaitu parameter gempa bumi, yang terdiri dari: event kejadian, letak episenter (latitude dan longitude), kedalaman, magnitudo gempa bumi. Data tersebut diperoleh dari portal data seismologi USGS (United States Geological Survey), dengan magnitudo 7,7 SR dan kedalaman $12 \mathrm{~km}$. Dengan daerah penelitian berlokasi di $9.3^{\circ} \mathrm{S}$ dan $107.4^{\circ} \mathrm{E}$.

Tahapan pengolahan data adalah sebagai berikut:

1. Menghimpun data parameter gempa bumi dari USGS sesuai dengan kriteria data (magnitudo, kedalaman, letak astronomis wilayah, dan event kejadian gempa bumi)

2. Mengkonversi seluruh magnitudo gempa bumi menjadi momen magnitude $(M w)$, karena magnitudo momen tidak mengalami saturasi. 
3. Memfilter data gempa bumi dengan tujuan untuk menghilangkan pengaruh foreshock dan aftershock. gempa bumi

4. Menghitung koefisien Gutenberg-Richter, nilai indeks seismisitas, serta periode ulang gempa bumi dengan metode kuadrat terkecil.

5. Mensimulasikan tsunami travel time yang menerjang pantai.

\section{HASIL DAN BAHASAN \\ Hasil}

\section{Focal Mechanism}

Memproyeksikan magnitude dan kedalaman gempa bidang sesar berupa bola fokus untuk kejadian gempa bumi secara otomatis dengan menggunakan data katalog
Global CMT (Centroid momen Tensor) berupa data strike, dip dan slip. Data yang digunakan bisa diakses langsung ketika akan menggunakan software mirone dengan koneksi data internet. Hasil dari keluaran Mirone berupa gambar bola fokus yang dapat di plot otomatis ketika dimasukkan data strike $290^{\circ}$, dip $10^{\circ}$, dan rake $102^{\circ}$. Berdasarkan hasil dari USGS mekanisme bola focus yakni oblique naik sehingga gempa tanggal 17 Juli 2006 menyebabkan tsunami.

\section{Perhitungan Magnitude dan Kedalaman Gempa}

Perhitungan menggunakan yang digunakan untuk menghitung parameter patahan (Wells dan Coppersmith, 1994). Dengan hasil sebagai berikut :

Magnitude Gempa : 7.7 SR
Kedalaman : $12 \mathrm{Km}$

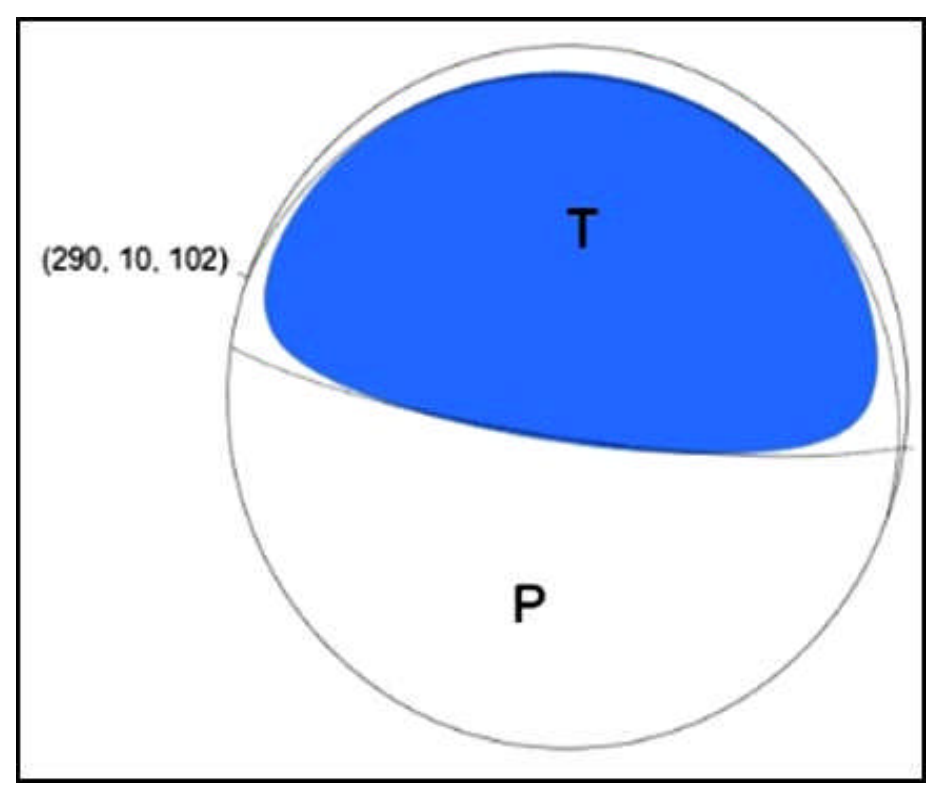

Gambar 3. Hasil mekanisme fokal USGS.

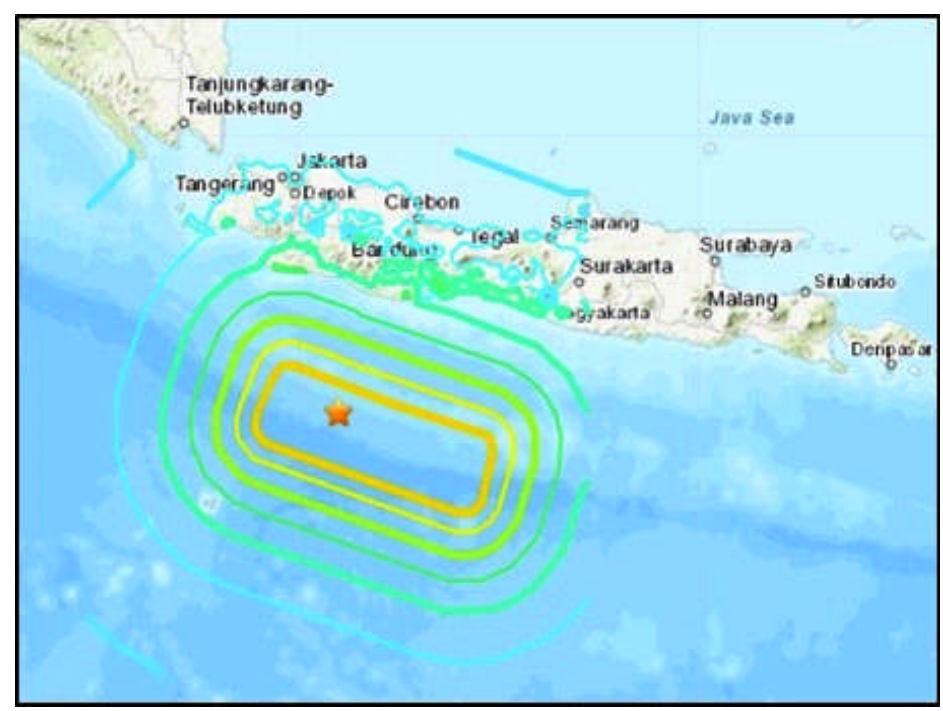

Gambar 4. Lokasi Gempa Bumi. 


\section{Simulasi Tsunami}

Langkah pertama yang dilakukan untuk membuat simulasi Tsunami yaitu menyiapkan data yaitu data sumber gempa berupa lintang, bujur daerah tunjangan tsunami, hasil perhitungan panjang patahan, lebar patahan, deformasi vertikal tanggal 17 Juli 2006. Data yang ditulis dalam source parameter selanjutnya akan digunakan sebagai data utama untuk pembuatan simulasi Tsunami.

Hasil perhitungan digunakan dalam proses pembuatan simulasi Tsunami menggunakan sebagai berikut.

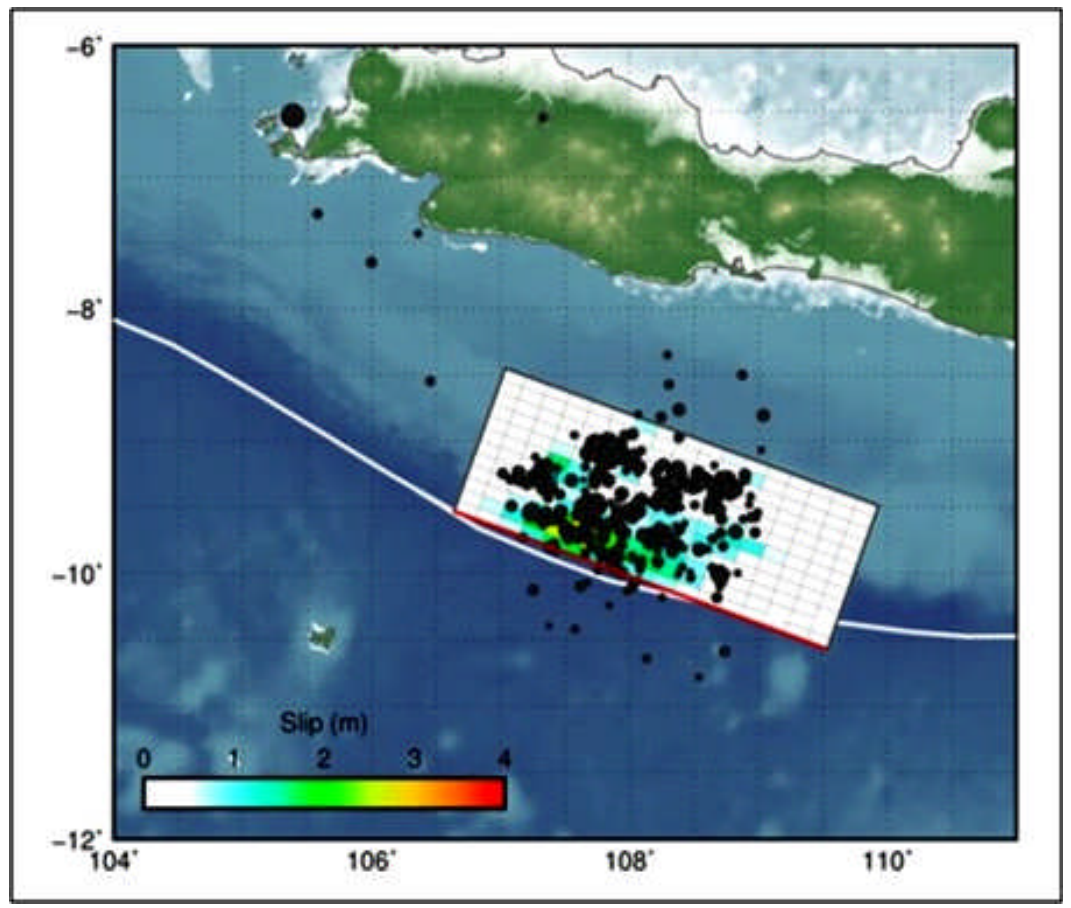

Gambar 5. Surface projection.

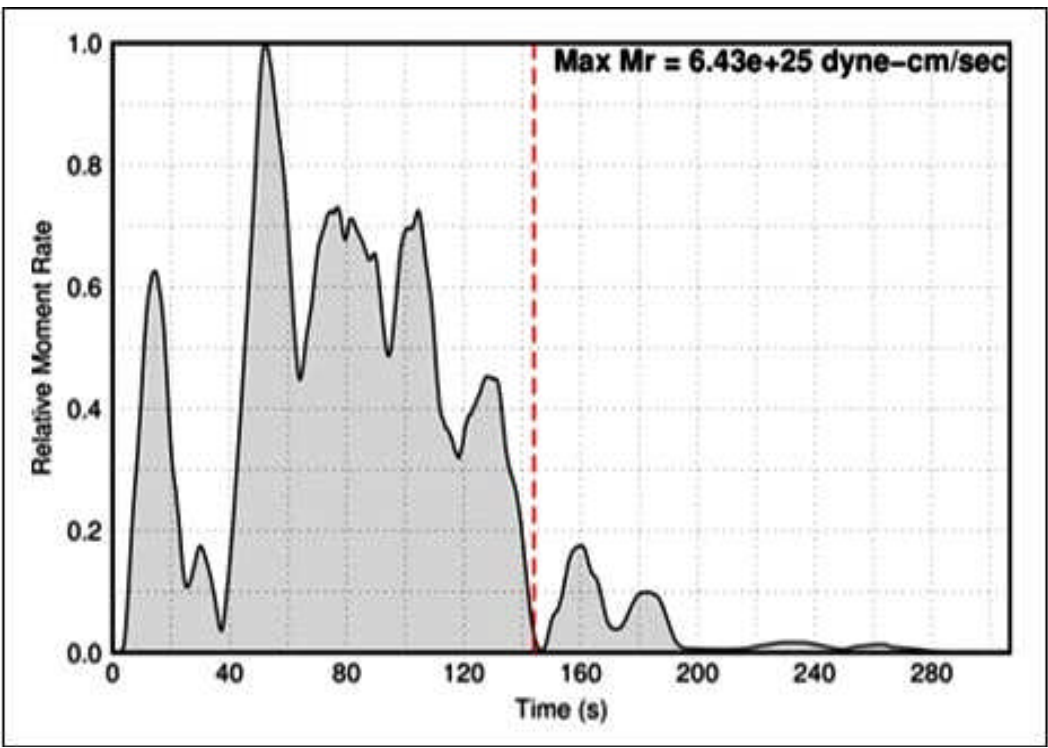

Gambar 6. Moment relative. 


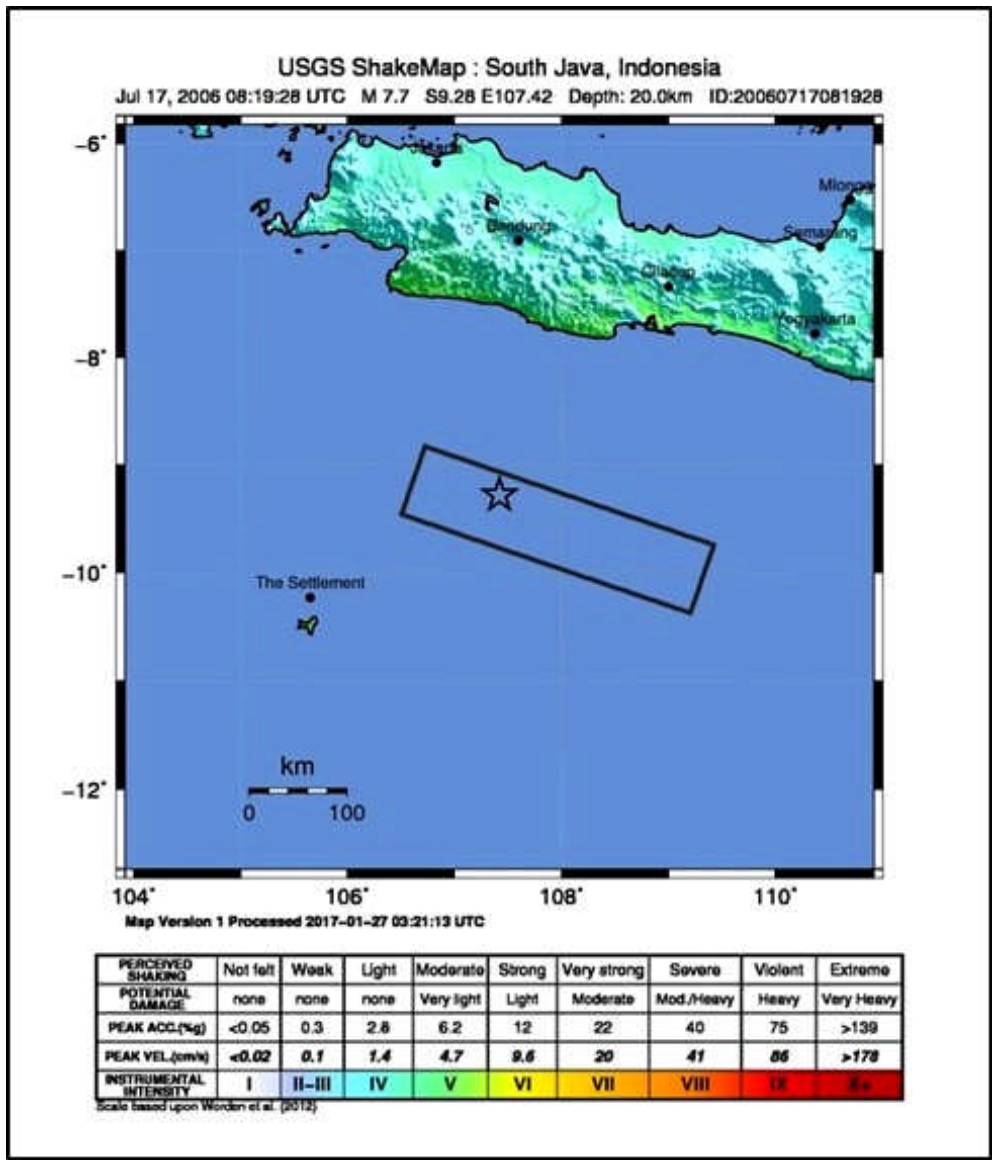

Gambar 7. Shake Map (USGS).

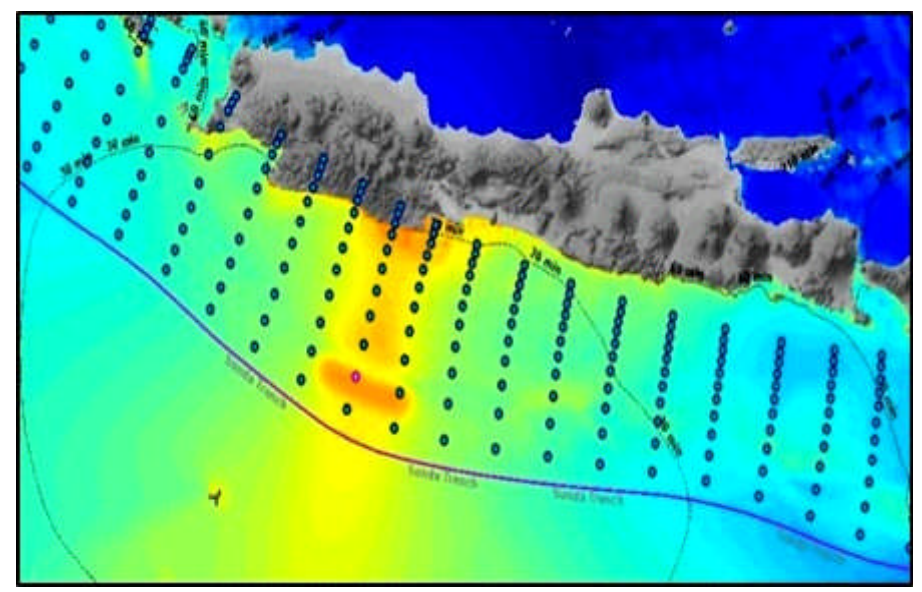

Gambar 8. Simulasi Tsunami.

\section{Bahasan}

Dari hasil simulasi yang dilakukan terlihat bahwa waktu yang ditempuh gelombang tsunami untuk mencapai pantai selatan Jawa Barat adalah 30 menit dari kejadian gempa.

Gambar diatas menjelaskan kondisi ekstrim gempa 7 Juli 2006 dengan kedalaman $12 \mathrm{~km}$ dibawah permulaan. Dilihat dari syarat terjadinya tsunami, gempa 7.7 SR ini menimbulkan Tsunami yang cukup besar, dan menimbulkan korban jiwa yang tidak sedikit, adanya kombinasi sesar yang terbentuk yaitu kombinasi sesar naik dan sesar mendatar.

\section{KESIMPULAN}

Berdasarkan analisis mekanisme bola fokus, menunjukkan bahwa gempa tanggal 17 Juli 2006 dengan koordinat $9.3^{\circ} \mathrm{S}$ dan $107.4^{\circ} \mathrm{E}$ adalah kombinasi sesar mendatar dan sesar naik atau jenis sesar ini disebut juga oblique. Gelombang tsunami pertama kali mencapai pantai pada waktu 30 menit setelah kejadian gempa, dalam hal 
ini yang pertama kali diterjang tsunami adalah pantai selatan Jawa Barat.

\section{DAFTAR PUSTAKA}

Aydan, O. (2008). Seismic and tsunami hazard potential in indonesia with a specialemphasis on Sumatra Island. Journal of The School of Marine Science and Technology. 6, 19- 38 .

Ha, T., Cho, Y.S. (2015). Tsunami propagation over varying water depths. Ocean. Eng.101, 67-77.

Olabarrieta, M., Medina, R., Gonzalez, M., \& Otero, L., (2011). C3: a finite volume-finite difference hybrid model for tsunami propagation and runup. Comput. Geosci. 37 (8), 1003-1014.
Kaharuddin, Hutagalung, R., \& Nurhamdan. (2011). Perkembangan tektonik dan implikasinya terhadap potensi gempa dan tsunami di Kawasan Pulau Sulawesi. Proceedings JCM Makassar. Makassar.

Sutrisno. (2007). Penentuan waktu datang gelombang tsunami di beberapa Kota Pantai Selatan Jawa Barat Sebagai Informasi Penting Dalam Usaha Penyelamatan secara Preventif Menghadapi Bencana Tsunami. Universitas Islam Negeri Syarif Hidayatullah, Jakarta.

Latief, H., Puspito, N.T., \& Imamura, F. (2000). Tsunami cata$\log$ and zones in Indonesia. Journal of Natural Disaster Science. 22(1), 25-43. 